\title{
¿Un nuevo a priori histórico? Análisis de propuestas de renovación de las Humanidades centradas en la noción de información
}

Recibido: 25/09/2019 | Revisado: 25/02/2020 | Aceptado: 17/03/2020

DOI: 10.17230/co-herencia.17.33.6

\author{
Roberto Rubio** \\ rorubio@uahurtado.cl \\ Pablo Esteban Rodríguez*** \\ prodriguez@sociales.uba.ar
}

\begin{abstract}
Resumen Este artículo analiza dos proyectos de renovación programática de las Humanidades, los cuales se centran en la noción de información. Consideraremos, por una parte, la propuesta de Friedrich Kittler acerca de un materialismo teórico-informacional y, por otra, la axiomática de las ciencias humanas de Gilbert Simondon. La pregunta que guía nuestro examen crítico es la siguiente: ¿de qué manera, en cada uno de esos proyectos, la noción de información funge como centro para una propuesta renovadora de las Humanidades? Nuestra hipótesis sostiene que hay un común denominador en ambas propuestas, el cual puede formularse en términos foucaultianos del siguiente modo: la información es entendida allí como el a priori histórico actual.
\end{abstract}

\section{Palabras clave:}

Información, a priori histórico, Simondon, Kittler, Foucault, Humanidades, posthumanidades.

\section{A New Historical a priori? Analysis of Proposals of Humanities Renovation Focused on the Notion of Information}

\footnotetext{
Abstract In this research work, two projects of programmatical renovation of humanities, which are focused on the notion of information, are analyzed. We will consider, on the one side, the proposal of Friedrich Kittler about a theoretical materialism of the information, and on the other side, Gilbert Simondon's human sciences' axiomatic. The question that guides our critical assessment is the following: in what ways, in each of these projects, the notion of information acts as center for a renovation proposal
}

* Este artículo hace parte de una investigación apoyada por el Centro de Estudios Mediales de la Universidad Alberto Hurtado e inscripta en el CONICET con sede en el Instituto de Investigaciones Gino Germani de la Universidad de Buenos Aires.

** Doctor en Filosofía de la Universidad de Friburgo. Director del Departamento de Filosofía de la Universidad Alberto Hurtado, Chile. ORCID: 0000-0002-2482-9062

*** Doctor en Ciencias Sociales de la Universidad de Buenos Aires. Investigador adjunto de ConicetInstituto Gino Germani Universidad de Buenos Aires, Argentina. ORCID: 0000-0003-0605-1899 
of humanities? Our hypothesis holds that there is a common denominator in both proposals, which can be formulated in Foucauldian terms as follows: the information is understood there as the current historical a priori.

\section{Keywords:}

Information, historical a priori Simondon, Kittler, Foucault, humanities, post-humanities.

La época actual presenta un especial desafío para las Humanidades tal como aún las conocemos. La escala de las transformaciones técnicas y de sus efectos es de tal envergadura que lo humano ha perdido centralidad como punto de referencia para la comprensión de los problemas y para el desarrollo de las posibles soluciones. Los objetos y modos de abordaje tradicionales de las Humanidades están puestos en cuestión, y junto con ello su propio estatuto y su idea programática. Como reacción a ello, proliferan nuevas concepciones que intentan renovar las Humanidades y a la vez hacer más profunda su autocrítica: Posthumanidades, Transhumanidades, Humanidades digitales, etcétera.

El presente trabajo analizará dos proyectos de renovación programática de las Humanidades, los cuales se centran en la noción de información. Consideraremos, por una parte, la propuesta de Friedrich Kittler acerca de un materialismo teórico-informacional y, por otra, la axiomática de las ciencias humanas, de Gilbert Simondon.

La pregunta que guía nuestro examen crítico es la siguiente: ¿de qué manera, en cada uno de esos proyectos, la noción de información funge como centro para una propuesta renovadora de las Humanidades? Nuestra hipótesis sostiene que hay un común denominador en ambas propuestas, el cual puede formularse del siguiente modo: la información es entendida allí como el a priori histórico actual.

Tomamos la noción de "a priori histórico" de Michel Foucault. En Las palabras y las cosas, dicha noción se utiliza, en el contexto de una arqueología de las ciencias humanas, para definir aquello que "desde el siglo XIX sirve de suelo casi evidente a nuestro pensamiento" (Foucault, 1997, p. 334).

Hay dos aspectos fundamentales en la noción de "a priori histórico" por los cuales recurrimos a ella para elaborar la relación entre las propuestas seleccionadas de Kittler y Simondon. Estos 
son, en primer lugar, el énfasis en instancias no formales que ofician de manera contingente como condiciones para una época determinada. Y en segundo lugar, la referencia a un proceso por el cual tales instancias prefiguran las prácticas y saberes, en particular las disciplinas humanísticas.

En cuanto designa un a priori no formal -en contraste con la noción kantiana de a priori-, la noción de a priori histórico puede aplicarse a procesos materiales y técnicos, como los sistemas de información. Esta posibilidad fue anticipada ya por Deleuze, quien señaló que las transformaciones producidas por las ciencias y las tecnologías basadas en la información obligaban a trazar un nuevo panorama epistémico (cfr. Deleuze, 2005, pp. 168-169).

Por su parte, el carácter histórico del a priori, conforme al uso que damos aquí a la noción, no conlleva compromisos teóricos maximalistas respecto a la historia. En otras palabras, no implica una noción de historia como flujo temporal lógicamente articulado en una totalidad de sentido, de modo tal que, con vistas a ello, se pudiera dar sentido (sea de modo progresivo o regresivo) a cualquier evento que ocurra. Lo histórico del a priori en cuestión consiste más bien en su carácter contingente y epocal. Se trata de condiciones que prefiguran un "conjunto transformable" (Foucault, 2002, p. 217). Dicho conjunto de saberes, prácticas e instituciones -lo que Foucault denomina "episteme"- tiene la forma temporal de una época. No se trata de una unidad cerrada de sentido, sino más bien de "un volumen complejo, en el que se diferencian regiones heterogéneas, y en el que se despliegan, según unas reglas específicas, unas prácticas que no pueden superponerse" (Foucault, 2002, p. 218).

Asimismo, la noción de a priori histórico corresponde a una indagación acerca de las condiciones del saber, particularmente de las ciencias humanas. Dicha noción no es pues, en principio, ajena a proyectos tales como el materialismo teórico-informacional o la axiomática de las ciencias humanas, y podría utilizarse para analizarlos. Esto no significa intentar reducir tales proyectos al enfoque de la arqueología foucaultiana, ni tampoco obviar las convergencias y distancias que alguno de esos proyectos (especialmente el de Kittler) tienen con ciertos planteamientos de Foucault. 
Desarrollaremos nuestra hipótesis en tres momentos. En primer lugar, mostraremos que Kittler describe a las tecnologías de la información como el principal condicionante de las prácticas y saberes en la época actual. En otras palabras, mostraremos -como algunos intérpretes ya han destacado- ${ }^{-1}$ que Kittler, tomando como base la noción foucaultiana de a priori histórico, plantea un a priori técnico-medial. Además de ello, analizaremos un cambio interno en la propuesta de Kittler que no ha sido discutido aún en profundidad: el pasaje de una versión débil hacia una versión fuerte, radicalizada, del a priori técnico-medial.

En segundo lugar, nos concentraremos en Simondon. Mostraremos cómo su propuesta de una nueva axiomática de las ciencias humanas se articula con una reivindicación del estudio de la técnica en su seno y, al mismo tiempo, con una apropiación crítica de la noción de información proveniente de la teoría matemática de Shannon. La propuesta de Simondon, "simétrica e inversa a la de Foucault" (Guchet, 2010, p. 12; traducción nuestra) en cuanto a la figura de lo humano, apunta a la cibernética en su condición de discurso que sitúa dicha teoría matemática en un marco más amplio de comprensión, pero que a la vez es necesario poner en tela de juicio.

Por último, pondremos en contraste la manera específica en la que, a nuestro juicio, los planteos de Kittler y Simondon elaboran el rol de la información en cuanto condición determinante de nuestra época. Nos concentraremos en la tensión entre la estrategia eliminacionista de Kittler, quien en su versión radicalizada del a priori técnico excluye todo otro orden que no sea el de los sistemas técnicos de la comunicación, y la estrategia simondoniana, que sitúa la cuestión de la información en el marco general de una teoría crítica de la comunicación que limita el alcance de la cuestión propiamente técnica. Para ello, analizaremos, por un lado, la relación entre información y sentido en Kittler, y por el otro, el vínculo entre información, señal y significación en Simondon.

1 Cfr. Ebeling (2006, p. 11); Gane (2005, p. 29); Mersch (2006, pp. 191-195); WinthropYoung (2006, p. 97). 


\section{La información como el a priori técnico-medial de nuestro tiempo: Kittler}

Friedrich Kittler, uno de los impulsores de las Ciencias de los Medios (Medienwissenschaften) y pionero de la German Media Theory, ${ }^{2}$ investiga el rol de los medios a partir de la siguiente premisa: "Los medios determinan nuestra situación" (Kittler, 1999, p. xxxix). ${ }^{3}$ La noción de "medios" puesta en juego allí es la siguiente:

Almacenamiento, transmisión y procesamiento de información: esa es la definición básica de medios en general. Los medios incluyen cosas pasadas de moda como los libros, cosas familiares como las ciudades y cosas nuevas como las computadoras (Kittler, 1999, p. 144).

La idea de que los medios, considerados a partir de la noción de información, son la condición determinante de nuestro tiempo, enlaza con una propuesta metodológica específica en Kittler, la cual consiste en aplicar el modelo matemático de la comunicación, elaborado por los pioneros de la informática, al estudio de la comunicación y la cultura: "Hay buenas razones para analizar los sistemas de comunicación como sistemas de información [...] La tríada de lo comunicado -mensajes, personas, bienes- se puede reformular en términos de la teoría de la información” (1993b, p. 170). Aquel modelo matemático que Shannon desarrolló con vistas a optimizar procedimientos de comunicación a distancia (telegrafía y telefonía) es utilizado por Kittler estratégicamente como punto de referencia para la construcción de un proyecto interdisciplinar sobre comunicación y cultura: "Olvidemos pues a los seres humanos, al lenguaje y al sentido, para dirigirnos en lugar de ello hacia las particularidades de los cinco elementos y funciones en Shannon" (Kittler, 2010, p. 44).

Los planteamientos de Kittler se sitúan en un escenario de tensión entre las ciencias de los medios, por una parte, y las ciencias de la cultura (Kulturwissenschaften), por otra. Frente a estas, el autor propone rehabilitar la dimensión técnico-medial. En un procedimiento arqueológico de inspiración foucaultiana, Kittler

2 Cfr. Geoghegan (2013); Pias (2016); Winthrop-Young (2006).

3 Las traducciones de las citas de los textos de Kittler son nuestras. 
pone de relieve los desarrollos tecnológicos específicos de los medios de comunicación como condiciones que posibilitan los procesos culturales, las prácticas y los saberes de una época (cfr. Kittler, 1999, p. $16 ; 2013$, pp. 154,170$){ }^{4}$

Con su proyecto, Kittler apunta a una transformación del campo general de las ciencias sociales y humanas, o mejor dicho, de las "Ciencias del Espíritu" (Geisteswissenschaften). La arqueología kittleriana combina la rehabilitación de los procesos técnico-mediales con un gesto de exclusión o expulsión. Se trata, como indica el título de una compilación de artículos editada por Kittler, de la "expulsión del Espíritu fuera de las Ciencias del Espíritu” (Kittler, 1990), lo que puede ser caracterizado también como la "expulsión del ser humano fuera de las Humanidades" (Kittler, 2017b, p. 1).

La "expulsión del Espíritu" y la focalización en los procesos técnicos de la comunicación, entendidos a partir de la noción de información, son dos aspectos distintivos de la propuesta de Kittler. Ambos se articulan como pars destruens y pars construens de un mismo programa, como lo muestra el siguiente pasaje: "Almacenar y transmitir información sin tener que recurrir a instancias tan oscuras como el "espíritu" o el "alma" humana: esa es la estricta definición de los medios" (Kittler, 2013, p. 153).

A continuación, analizaremos dicho programa, al que Kittler (1993a) caracteriza como "materialismo teórico-informacional [informationstheoretischen Materialismus]" (p. 182). En nuestro análisis pondremos especial atención en la centralidad que la noción de información allí adquiere. Mostraremos cómo el autor nos invita a pensar la información como un a priori técnico-medial y con ello, conforme a nuestra interpretación, como el nuevo a priori histórico. Además, y avanzando hacia espacios de discusión aún poco trabajados por los críticos, examinaremos dos versiones, una débil y otra fuerte, de la teoría kittleriana acerca del a priori técnico-medial.

4 Respecto al método arqueológico en Kittler y su influencia en la reciente arqueología medial, cfr. Ebeling $(2006,2017)$ y Mersch $(2006$, pp. 188-191). 
El materialismo teórico-informacional de Kittler entiende a la mediación comunicativa como procesos de transmisión, almacenamiento y procesamiento de datos y señales. ${ }^{5}$ Según ello, los medios no son otra cosa que los procedimientos y materialidades correspondientes a tales procesos. El núcleo de dicha concepción es la información, entendida matemáticamente. Se trata de una magnitud probabilística gracias a la cual se puede gestionar un sistema de envío y recepción de datos y señales a distancia.

Para entender mejor por qué la información es el centro de la propuesta de Kittler, conviene considerar el enfoque de Shannon y la recepción que Kittler realiza de él. Para Shannon, un aspecto central del problema técnico de la comunicación a distancia es la incerteza. Este autor localiza la incerteza principalmente en dos lugares del sistema de comunicación: en la fuente de los mensajes, y en el canal o medio. En otras palabras, advierte que no es posible saber con plena certeza si el mensaje decodificado y recibido corresponde exactamente al mensaje emitido y codificado, y que tampoco es posible saber con plena certeza qué elementos del mensaje recibido corresponden a distorsiones o interferencias ocurridas durante la transmisión. Ahora bien, en conexión directa con esa manera de entender el problema surge la propuesta de solución. La estrategia central consiste en gestionar la incerteza mediante el cálculo de probabilidades. Allí juega su rol específico el concepto matemático de información.

Es importante aquí tener en cuenta la distinción entre la incerteza indeseable, esto es, la inevitable intervención de interferencia y ruido, y la incerteza deseable. Esta última consiste en la impredecibilidad gracias a la cual una comunicación no se vuelve innecesaria. La noción de información, expresada por Shannon en una fórmula matemática, apunta precisamente a cuantificar la incerteza deseable del sistema de comunicación. Pensada desde la simplicidad de una base binaria, la fórmula indica que, en el caso de que el conjunto

5 En más de una ocasión, Kittler utiliza expresiones como "transmisión de información" y "transmisión de datos" sin distinguirlas mayormente. A fin de evitar posibles malentendidos, cabe decir que el autor refiere con ello a la transmisión de datos y señales, estructurada y gestionada conforme a la noción probabilística de información. Asimismo, Kittler (1993b) entiende al sistema que articula las operaciones de transmisión, almacenamiento y procesamiento como un "sistema de información" (p. 170). 
de mensajes elegibles sea dos, y ambos sean igualmente probables, el valor de la información será uno. Sobre esta base se establece un procedimiento para calcular la información mediante números binarios o bits. ${ }^{6}$ Como se puede apreciar, aquí el término "información" no refiere a ningún sentido o contenido semántico de los mensajes. Con respecto a ello, Weaver, en el texto explicativo que acompaña a la teoría matemática de la información planteada por Shannon, ${ }^{?}$ sostiene que el problema semántico concerniente a la relación entre el significado de los mensajes y su referente externo es secundario y derivado respecto al problema técnico acerca de la exactitud en la transmisión de las señales y datos (cfr. Shannon y Weaver, 1949, p. 6).

Conforme a lo expuesto, podemos destacar tres aspectos de especial importancia para Kittler en su recepción de la teoría matemática de Shannon. En primer lugar, la descripción técnica de la comunicación a distancia como flujo de señales codificadas que han de ser decodificadas. En segundo lugar, el acento en la incerteza como clave para la gestión -probabilística- del sistema. Y en tercer lugar, aunque con no menos importancia, el carácter secundario de la dimensión semántica respecto a la dimensión técnica de la comunicación.

Durante sus investigaciones sobre las técnicas de la información en el siglo Xx, Kittler complementará su noción de información con aspectos centrados en la gestión del flujo de señales y datos mediante procesamiento algorítmico. Así, para Kittler (1993b, p. 170; 2017, p. 24), la información no es solamente una magnitud probabilística, sino que también refiere a la gestión de órdenes, comandos o instrucciones que conducen hacia una destinación específica. Esto será de especial interés para sus indagaciones sobre la conexión entre la industria bélica y los desarrollos de la tecnología informacional.

El materialismo teórico-informacional de Kittler puede ser descrito, según lo expuesto hasta aquí, como un enfoque sobre la

6 Para una presentación detallada de la noción matemática de información, cfr. Clarke (2010).

7 El artículo "Recent Contributions to the Mathematical Theory of Communication", de Warren Weaver, precede al artículo de Claude Shannon "The Mathematical Theory of Communication", en el libro The Mathematical Theory of Communication. El libro, publicado en 1949, se compone de ambos textos. El artículo de Weaver es una introducción al artículo de Shannon, cuya versión original había sido publicada en 1948. 
cultura y la comunicación, centrado en la noción matemática de información y focalizado en las técnicas y procedimientos para administrar los flujos de datos y señales, un enfoque que excluye la noción de "espíritu" y otras nociones afines que refieran a instancias agenciales subjetivas o intersubjetivas.

Ahora bien, es importante señalar que Kittler recurre a la noción foucaultiana de a priori para definir el rol de las técnicas y medios informacionales. En este sentido, en Gramophone, Film, Typewriter, Kittler afirma: "Las distinciones metodológicas del psicoanálisis moderno claramente coinciden con las distinciones de las tecnologías de los medios. Cada teoría tiene su a priori histórico. Y la teoría estructuralista solamente deletrea aquello que, desde el cambio de siglo, ha estado llegando en los canales de información" (1999, p. 16).

El pasaje citado da a entender que la tecnología de la información constituye el nuevo a priori histórico. A su vez, la referencia explícita a la noción foucaultiana de "a priori histórico" va de la mano con una crítica a la teoría estructuralista. La idea de fondo para esa crítica es la siguiente: la teoría estructuralista intenta descifrar desde el paradigma de la escritura y de los textos los saberes y prácticas que emergen hacia el final del siglo XIX. Y dado que estos están estructurados informacionalmente, la teoría estructuralista no es capaz de alcanzar el correspondiente a priori, y por ello solamente lo "deletrea".

Esta objeción al enfoque estructuralista conecta con una crítica directa de Kittler a Foucault, según la cual el análisis del discurso está orientado a procesos desarrollados bajo el monopolio de la escritura y por ello no es capaz de examinar apropiadamente las técnicas informacionales que determinan la comunicación y la cultura desde la segunda mitad del siglo XIX. En palabras de Kittler: su concepto de archivo "[...] designa un a priori histórico de oraciones escritas. De allí que los estudios de análisis del discurso hayan tenido problemas con períodos cuyos métodos de procesamiento de datos destruyeron el monopolio del almacenamiento y transmisión alfabéticos [...]" (1985, p. 359 [1990, p. 369]; cfr. Kittler, 2002, p. 39). Junto con esta crítica, Kittler propone para nuestro tiempo una arqueología medial que esté dirigida hacia las técnicas de la información: "Las arqueologías del presente deben pues tomar en consideración el almacenamiento de datos, la transmisión y el cálculo en los medios 
técnicos" (Kittler, 1985, p. 359 [1990, p. 369 ss.]). Lo que constituye la condición material de una época, de sus saberes y discursos, es, para Kittler, "el a priori tecnológico de sus medios" (1999, p. 117). ${ }^{8}$

Diversos intérpretes han señalado el paso desde la arqueología foucaultiana, enfocada en el a priori histórico, hacia la arqueología medial de Kittler, orientada hacia el a priori técnico-medial. ${ }^{9}$ Algunos investigadores, como Wolfgang Ernst y Knut Ebeling, han puesto además especial acento en las diferencias y contrastes entre esos dos enfoques. ${ }^{10}$ En relación con ello, cabe preguntar: ¿conlleva el énfasis de Kittler en las técnicas de la comunicación un rechazo de la noción foucaultiana de "a priori histórico"? La cita de Gramophone, Film, Typewriter antes comentada (1999, p. 16) sugiere que no. Ahora bien, esa cita conecta con la crítica a los enfoques centrados en "el monopolio de la escritura" (Kittler, 1985, p. 359 [1990, pp. 369 ss.]), entre los cuales Kittler reconoce también a la arqueología foucaultiana. Desde una consideración matizada, se pueden señalar dos aspectos relevantes para esta cuestión. Por un lado, la arqueología del presente que promueve Kittler pone de relieve un específico modo de relación entre tiempo y espacio que las técnicas de la información producirían gracias a su capacidad para manipular el eje temporal. ${ }^{11}$ En ese sentido, para algunos intérpretes, el a priori técnico-medial no podría ser estudiado desde un enfoque orientado hacia la temporalidad propia de las formaciones discursivas, y menos aún sería accesible desde tipos de saber que se proponen esclarecer sus objetos incorporándolos en el curso de una historia, como, por ejemplo, la historia cultural de los medios. ${ }^{12}$ Por otro lado, sin embargo, en el marco de su materialismo teórico-informacional, Kittler entiende al a priori técnico-medial como el conjunto de

8 Los críticos hablan del "a priori técnico" (Ebeling, 2006, p. 11; Gane, 2005, p. 29; Mersch, 2006, pp. 191-195) y del "a priori técnico-medial" (Hartmann, 2008, p. 251). El término "technisch", utilizado por Kittler, puede ser traducido al español como "técnico/a" y "tecnológico/a", alternativamente. En inglés suele ser traducido como "technological".

9 Cfr. Ebeling (2006, p. 11, 20); Gane (2005, pp. 28 ss.). Para una consideración general sobre la recepción de la arqueología foucaultiana por parte de Kittler, véase Hartmann (2008, p. 252), Mersch (2006, pp. 191-195), Winthrop-Young (2006, p. 97).

10 Cfr. Ebeling (2006, pp. 20 ss.; 2017); Ernst (2013). Agradecemos a la evaluadora o evaluador anónimo de la revista Co-herencia por dirigir nuestra atención sobre este punto.

11 Cfr. Ebeling (2006, pp. 21 ss.); Krämer (2006).

12 Cfr. Ebeling (2006, pp. 21 ss.); Ernst (2013, pp. 134 ss.; 137 ss.). 
condiciones técnicas que definen una época, el cual entra en relaciones de continuidad y discontinuidad con los a priori técnicos de otras épocas. En este sentido, cabe mencionar la tesis kittleriana según la cual el código binario y la tecnología de la computación consuman el proyecto de un alfabeto universal, proyecto que había sido concretado inicialmente y de manera incompleta por los griegos (cfr. Kittler, 2004, p. 249; 2009, p. 24; 2017, p. 65).

En vista de lo anteriormente expuesto, se puede afirmar que las técnicas de la información constituyen para Kittler condiciones epocales que entran en relación de continuidad y discontinuidad con las condiciones de otras épocas. En tal sentido, pueden ser consideradas como un a priori histórico. Ahora bien, el énfasis de Kittler en la peculiar organización de las relaciones de tiempo y espacio por parte de las técnicas informacionales ha dado lugar a planteamientos que, yendo más allá de Kittler, extreman el contraste entre el enfoque de la arqueología medial y todo enfoque que utilice la estructura de la historia para explicitar los cambios técnicos y culturales. Tales planteamientos rechazan la noción de a priori histórico. Respecto a ello, cabe decir lo siguiente: en primer lugar, a la luz de dichos planteamientos se ponen en evidencia tensiones al interior del pensamiento de Kittler y también entre sus posibles líneas de desarrollo. En segundo lugar, a tales planteamientos les cabe la tarea de elaborar una estrategia que permita explicar cambios, continuidades y discontinuidades, sin recurrir a nociones tales como las de época.

Volviendo a la consideración kittleriana acerca del a priori técnico-medial, corresponde ahora concentrarnos en un aspecto que no ha sido aún considerado suficientemente por la crítica. Nos referimos a la variación, por parte de Kittler, en su apropiación de la teoría foucaultiana del a priori. En efecto, es posible advertir dos planteamientos de Kittler, a los que podemos caracterizar como la versión débil y la versión fuerte del a priori técnico-medial.

El primer planteamiento corresponde principalmente al texto Sistemas de inscripción 1800-1900.13 Allí, Kittler reconduce prácticas

13 Es importante aquí hacer una observación respecto al título del texto. La versión en alemán Aufschreibesysteme ha sido traducida al inglés como "Discourse networks" (redes discursivas). Una traducción bastante literal del texto alemán sería: "sistemas de inscripción" - y de hecho, Parikka (2012, p. 69) propone traducirlo al inglés como "system 
y discursos (por ejemplo, aquellas correspondientes a la alfabetización en Alemania en el siglo XIX) hacia sistemas técnicos de configuración y gestión de datos culturalmente relevantes, como, por ejemplo, el silabario de Heinrich Stephani (cfr. Kittler, 1985, pp. 37-47). El principio metodológico de fondo que opera en su trabajo consiste en diferenciar dos niveles de análisis: por una parte, el orden de los discursos, y por otra, el de los sistemas de inscripción, fundante de aquel.

El segundo planteamiento se desarrolla en el contexto de los estudios kittlerianos sobre los medios técnicos de comunicación del siglo Xx. Lo característico de este planteamiento es una estrategia monista que considera de manera exclusiva -y excluyente- el orden técnico-medial. Los procesos de mediación ya no son entendidos como procesos de un orden propio (cultural, discursivo), el cual se fundaría en una infraestructura técnica. A diferencia de ello, se entiende que el orden propio de lo que habitualmente llamamos procesos culturales no es otro que el de los sistemas y redes de información.

En esta versión fuerte del a priori se cumple el proyecto de "expulsión del Espíritu", que viene a radicalizar el gesto de Shannon y Weaver, extrapolado ahora al campo general de las ciencias sociales y humanas. Ya no se trata de que la dimensión semántica quede subordinada al planteamiento y a la solución de cuestiones técnicas. Se trata, más bien, de que todo el orden de la comunicación puede ser descrito exclusivamente en términos técnicos, más precisamente: como el orden de los sistemas de información.

Junto con ello, tiene lugar la incorporación de la dimensión ontológica a la discusión. En este sentido, Kittler (1993a) afirma: "Solamente existe aquello que se puede encender, apagar o conectar" (p. 182). Por su parte, como profundización de esta versión ontológica monista, Kittler avanza hacia la comprensión de la información como una propiedad estrictamente material, en el sentido de la posibilidad de diferencias iterables en procesos físicos elementales. ${ }^{14}$ Con ello,

of inscription"-. El título de la traducción al inglés actualmente vigente no solo reemplaza "sistema" por "red", sino que además sugiere asociaciones muy directas con la noción foucaultiana de "discurso" que no están indicadas en el título en alemán.

$14 \mathrm{Al}$ respecto, Gane (2005) afirma: "La información ya no es tratada puramente como una función probabilística (como lo fue para Shannon y Weaver), sino como una propiedad material que no se distingue de los componentes físicos que la hacen posible" (p. 29). 
interviene en el campo de discusión de la ontología de los medios. El curso de sus investigaciones en este campo quedó trunco con su deceso. ${ }^{15}$

\section{La información en el marco de la cibernética: Simondon}

En 1960, seis años antes de la publicación de Las palabras y las cosas y nueve antes de la publicación de La arqueología del saber, Simondon pronunció ante la Sociedad Francesa de Filosofía la conferencia "Forma, información, potenciales". ${ }^{16}$ Propuso allí una renovación de los presupuestos de las ciencias humanas, alejada tanto del estructuralismo como de la fenomenología entonces imperantes, y que se puede resumir en cuatro puntos:

Primero: según Simondon, hay que fundar una axiomática de las ciencias humanas que permita unificar su campo de investigaciones. Se trata de superar las dicotomías entre individuo y sociedad, por un lado, y entre psicologismo y sociologismo, por el otro. Estas impedirían una visión de conjunto de los fenómenos psicosociales como actos de transformación en los que el medio interior y el medio exterior de las acciones se modifican de manera permanente bajo el pulso de la interacción.

Segundo: el punto de partida en esta axiomática polarizante de las ciencias humanas es la noción de campo, tomada de la física, y convertida en la cuestión de la forma por la teoría psicológica de la Gestalt. El concepto de campo "establece una reciprocidad de estatus ontológicos y de modalidades operatorias entre el todo y el elemento", pues el elemento "recibe la influencia del campo, está sometido a las fuerzas del campo" y al mismo tiempo "interviene en el campo a

15 Particularmente en la última fase de su pensamiento, caracterizada por un especial interés en la música y la ciencia griegas, Kittler interviene en la discusión ontológica. Cabe destacar allí, por una parte, su interpretación de la historia del ser heideggeriana, y por otra, su tendencia hacia una ontología materialista de los medios. Cfr. Kittler (2004, pp. 249-251; 2009).

16 Guchet (2010) señala que Simondon comparte con Foucault el hecho de que hay algo "impensado en las ciencias humanas" y la denuncia de que "no hay ontología posible en el caso del hombre", pero allí donde la empresa de Foucault busca "describir el orden del discurso en el seno del cual se desplegó históricamente el tema antropológico”, la de Simondon busca anclar este tema en una nueva "ontología" que deseche "los postulados metafísicos inadecuados" de las ciencias humanas (pp. 13-14). 
título creador y activo, modificando las líneas de fuerza del campo y la repartición del gradiente" (Simondon, 2015, p. 492, énfasis en el original). Con respecto a ello, Simondon advierte que la Gestalttheorie privilegió las configuraciones estables, la buena forma, pues si la interacción entre el campo y los elementos se define como "una configuración común al campo exterior y al campo interior", la estructura resultante será "considerada como el resultado de un estado de equilibrio" (Simondon, 2015, p. 494, énfasis en el original).

Tercero: de acuerdo con Simondon, la formulación de la teoría de la información, tanto en Claude Shannon como en Norbert Wiener -sin tener en cuenta las importantes diferencias entre ambos enfoques-, permite recuperar el problema de la interacción en la medida en que las configuraciones que busca dicha teoría no aluden a estados determinados, sino tan solo probables, continuando los desarrollos de la física derivada de la noción de campo en un sentido diferente al de la Gestalttheorie. La información es una cantidad que se mide en relación "a lo inverso de una probabilidad", de manera que "si se envía un mensaje, si se procura uno, es porque el estado del objeto no es conocido". Esto quiere decir que, si el mensaje es la relación que se establece entre el polo emisor y el polo receptor, entonces "al interior del esquema completo, la información no es definible a partir de un único término, como la fuente, o como el receptor, sino a partir de la relación entre fuente y receptor (Simondon, 2015, p. 497, énfasis en el original). Sin embargo, dado que la teoría de la información busca "la correlación entre emisor y receptor en los casos en los que hace falta que exista dicha correlación", se asiste a una paradoja: "cuanto más estrecha es la correlación entre el emisor y el receptor, menor es la cantidad de información" (Simondon, 2015, p. 498, énfasis en el original). En otros términos, si la información en teoría es sinónimo de interacción en un campo de estados improbables, en la práctica ligada a las tecnologías de información busca lo contrario: la probabilidad y la previsibilidad. Esta es la razón por la cual, según Simondon, para aplicar la teoría de la información al dominio psicosocial "habría que suministrar un término no probabilístico" que él identifica como "una cualidad de información o de una tensión de información" (Simondon, 2015, p. 498, énfasis en el original). En este punto, pues, el filósofo francés propone reemplazar la noción de información por la de energía 
potencial, cerrando así el círculo de su conferencia: de la forma a la información y de la información a los potenciales.

Cuarto: La relación entre estos tres términos puede ser interpretada, dice Simondon en el inicio de la conferencia, a partir del objeto técnico, el cual "está destinado a servir de modelo, de ejemplo, quizás de paradigma" (Simondon, 2015, 483, énfasis en el original) de ese vínculo. Dicho de otro modo, mientras el estructuralismo situaba al lenguaje y la fenomenología al sujeto de conocimiento como modelo de comprensión para las ciencias humanas, Simondon concebía a la técnica, junto a la noción física de campo y por intermedio de la teoría de la información, como la sede de una nueva axiomática para las Humanidades.

Para comprender mejor el proyecto de dicha axiomática, es preciso abordar dos cuestiones fundamentales. En primer lugar, si el objeto técnico es un modelo para introducir la cuestión de la interacción y la noción de campo en las ciencias humanas (punto cuarto), pero al mismo tiempo la teoría de la información en su versión más tecnológica es inadecuada para buscar la axiomatización de estas ciencias (punto tercero), ¿es necesario distinguir entre objetos técnicos en general e informacionales en particular? Y en segundo lugar: ¿la teoría de la información está tensionada entre una interpretación tecnicista y reduccionista y otra más compleja y articulable con el propósito simondoniano?

Para dar respuesta a estas preguntas consideraremos tres momentos en la elaboración de la noción de información por parte de Simondon: uno relativo al vínculo general entre técnica y cultura en la modernidad, otro en el cual el filósofo francés interviene en el debate sobre la definición de información que se dio en el seno de la cibernética, y un tercer momento en el que Simondon sitúa a la información dentro de su proyecto general de una teoría de la individuación para definir la cuestión informacional en términos de "amplificación".

En El modo de existencia de los objetos técnicos (MEOT) su tesis secundaria de doctorado, defendida en 1958, Simondon sigue la estela de la propuesta de Ernst Cassirer (cfr. Hoel y Van der Tuin, 2013) al sostener que las ciencias humanas y las ciencias de la cultura en general no han considerado apropiadamente el papel de 
la técnica en la definición de los saberes humanistas. Junto con ello, Simondon critica el enfoque tecnofóbico característico de la filosofía tradicional de la técnica en el siglo xx, desde M. Heidegger hasta J. Ellul. Así, ya en las primeras palabras de MEOT, Simondon (2008) denuncia una definición de cultura que "ignora en la realidad técnica una realidad humana" y llama a la filosofía a promover una "toma de conciencia de los modos de existencia de los objetos técnicos", "un deber análogo al que cumplió en la abolición de la esclavitud y la afirmación del valor de la persona humana" (2008, p. 31). De manera enfática, Simondon afirma que

la oposición que se ha erigido entre la cultura y la técnica, entre el hombre y la máquina, es falsa y sin fundamentos; solo recubre ignorancia o resentimiento. Enmascara detrás de un humanismo fácil una realidad rica en esfuerzos humanos y en fuerzas naturales, y que constituye el mundo de los objetos técnicos, mediadores entre la naturaleza y el hombre (2008, p. 31).

Así, pues, para Simondon no existe "la" técnica como problema, sino que corresponde historizar los vínculos cambiantes entre los seres humanos y sus objetos técnicos para circunscribir los desafíos que supone la introducción de la información. Hasta la Revolución industrial, la actividad técnica suponía una capacidad somática, la humana, unida a elementos técnicos: la herramienta (martillo, destornillador, sierra, etc.) o instrumento (el microscopio como herramienta de percepción, por ejemplo). El siglo XIX marcó el ingreso de los individuos técnicos, a veces identificados con las máquinas termodinámicas, que en lo esencial toman a su cargo la función de portación de herramientas antes centrada en el cuerpo humano; de allí que se planteara la competencia entre seres humanos y máquinas. Dicha competencia, sostiene Simondon, es real y provoca sentimientos de alienación, pero ya a mediados del siglo Xx, con el ascenso de la cibernética y la teoría de la información, deja de ser un criterio válido para juzgar la actividad técnica humana.

Efectivamente, y a diferencia de Kittler, la cuestión de la información comienza para Simondon cuando, a través de los mecanismos de autorregulación, se planteó un "uso de los canales de información" que es "diferente de los canales energéticos en las máquinas", lo cual supone "una modificación muy profunda de la 
filosofía de las técnicas" (Simondon, 2008, p. 147). La información como tema de investigación y la cibernética como discurso sobre ese tema hacen que "la finalidad y la organización" pueden "ser pensadas y creadas racionalmente, puesto que se convierten en materias de técnicas" (2008, pp. 123-124). Se abre así la etapa de los conjuntos técnicos, en la cual la imagen de la competencia con la máquina, o la del sometimiento de la actividad técnica al trabajo con las herramientas, debe ser reemplazada por la del ser humano como "director de orquesta", "coordinador e inventor permanente de las máquinas que están alrededor de él” (pp. 33-34).

Conforme a lo anterior, la noción de información se inscribe en el contexto de una transformación general de las condiciones de la actividad técnica, esto es, el ascenso de la industria moderna y sus saberes asociados, que obliga a reconsiderar la definición de cultura. Teniendo en cuenta tal transformación y sus efectos en la concepción misma de cultura, Simondon considera que los objetos informacionales son diferentes de los objetos técnicos en general. Con esto queda aclarada en gran medida la primera cuestión. Volveremos sobre ella al final de esta sección.

Para avanzar respecto a la segunda cuestión, consideremos a continuación los avances de Simondon respecto a la noción de información en relación con las propuestas de la cibernética. De acuerdo con la definición clásica de Norbert Wiener, la cibernética es la ciencia que estudia la comunicación y el control en animales y máquinas ${ }^{17}$ y la piedra de toque para organizar esta equivalencia, no solo entre animales y máquinas, sino también entre estos y los seres humanos, es la información, entendida como un nuevo elemento, diferente de la materia y de la energía (cfr. Wiener, 1971, p. 216). El segundo movimiento fundamental de la cibernética es su aspiración a constituir un campo interdisciplinario alrededor de estas definiciones, de manera tal de expandir la cuestión de la información desde la técnica y la biología hacia las ciencias humanas, tal como se observa en la historia de las denominadas "conferencias Macy" (Dupuy, 1999; Heims, 1991; Rodríguez, 2012; Triclot, 2008). Como indica

17 Cybernetics or control and communication in the animal and the machine es el título original del libro de 1948. 
Hui (2015), Simondon se detiene en la octava conferencia Macy, donde se produce un debate entre Shannon y Donald MacKay, quien afirmaba que no era posible, como proponía Shannon, hacer abstracción de la significación para dar cuenta de la eficacia de la transmisión de información a través de una señal.

Según Simondon, esa discusión obliga a distinguir netamente entre señal e información. La señal "es la decisión entre dos estados posibles" (Simondon, 2015, p. 279). En virtud de ello, Simondon asume que la condición primaria de su efectuación es una cierta imprevisibilidad de estados. Sin embargo, prosigue el autor, "en otro sentido, la información es aquello que implica regularidad y retorno periódico, previsibilidad. La señal es tanto más fácil de transmitir cuanto más fácilmente previsible" (Simondon, 2015, p. 281). Esto es una paradoja si se la analiza desde la posición de emisión de la transmisión o desde la estructura del mensaje transmitido, que es lo que hace la teoría matemática de la información, denominada por Simondon teoría "tecnológica" de la información. Sin embargo, la situación es diferente si se entiende que la información depende de la posición de recepción. En este sentido, Simondon (2015) afirma:

Como en general los problemas relativos a la información son problemas de transmisión, los aspectos de la información únicamente retenidos y sometidos a la apreciación tecnológica son aquellos relativos a la no degradación de las señales en el curso de la transmisión; el problema de la significación de las señales no se plantea [...] es el sujeto humano quien es receptor al final de la línea de transmisión, del mismo modo que lo sería si ninguna distancia lo separara del origen de las señales. Por el contrario, el problema es muy diferente cuando las señales no son solamente transmitidas técnicamente, sino también recibidas técnicamente, es decir recibidas por un sistema dotado de funcionamiento propio y que debe integrarlas a ese funcionamiento. Encontramos entonces que las magnitudes relativas a la transmisión de las señales y las que son relativas a su significación son antagonistas (p. 282).

Es importante subrayar que Simondon incluye en la posición de recepción tanto al "sujeto humano" como a cualquier "sistema dotado de funcionamiento propio", por lo que la distinción entre señal y significación no se relaciona con una dualidad entre lo técnico y lo 
humano, ${ }^{18}$ sino más bien con la posibilidad de "suministrar un término no probabilístico a la teoría de la información" (Simondon, 2015, p. 498, énfasis en el original). Así, si la señal (información entendida como cantidad) es "lo que es transmitido", y la forma (información entendida como cualidad) es "aquello en relación a lo cual la señal es recogida en el receptor” (Simondon, 2015, p. 284), la significación es lo que surge en la relación que se establece entre la señal y la forma en el receptor y solo es comprensible en tanto este receptor está "en funcionamiento", o sea, es "un sistema con estructuras y potenciales" (Simondon, 2015, p. 285). La significación es "la experiencia de disparidad que refiere a la señal extrínseca y a la forma intrínseca" (Simondon, 2015, p. 284). De esta manera, el filósofo francés apunta a entender a la información como tensión, más que como cantidad o cualidad (cfr. Simondon, 2015, p. 498), algo que sobreviene cuando la significación como disparidad es algo "efectivamente integrado al funcionamiento del receptor" para futuros intercambios (Simondon, 2015, p. 284).

Para comprender cabalmente esta distancia entre la señal y la significación, es preciso tener en cuenta el proyecto del filósofo francés de incluir la teoría de la información dentro de una teoría filosófica de la individuación. Información e individuación se vinculan desde los ejes de la conferencia Forma, información, potenciales, planteados anteriormente: una axiomática de las ciencias humanas basada en la interacción y en la definición de polaridades (de allí la tematización de la tensión de información), una recuperación de la noción de campo que vincula estructuras con operaciones y una reforma de la noción de información que corrija la tendencia tecnicista y reduccionista de la teoría de Shannon. El denominador común de todos estos ejes es la consideración de la información como acción: más precisamente, un tipo de relación entre forma y materia atravesado por procesos de autorregulación y transmisión.

Esta reforma de la noción de información fue presentada por Simondon ante un público compuesto por cibernéticos provenientes de varias disciplinas (incluyendo al propio Wiener), en ocasión del

18 De hecho, Simondon (2015) aclara que el hecho de que "una señal reciba una significación" no ocurre "solamente en un contexto psicológico", sino también "en un intercambio de señales entre objetos técnicos" (p. 283). 
coloquio de Royaumont sobre la noción científica de información, que él mismo organizó en 1962. En esa conferencia, Simondon presentó a la información como un tipo de "amplificación" que relaciona estructuras con operaciones, siguiendo planteamientos presentados anteriormente con miras a la construcción de una allagmática o ciencia de las operaciones: "[...] la información no es una cosa, sino la operación de una cosa que llega a un sistema y que produce allí una transformación" (2016, p. 139). ${ }^{19}$

Para Simondon, existen tres tipos de amplificación de información: una transductiva, según la cual la operación compromete la transformación de toda la estructura, como en el caso de un proceso de cristalización o, en sentido técnico, el moldeado de un ladrillo; una moduladora, por la cual la operación transformadora no alcanza a modificar toda la estructura porque "se obtiene al domesticar la propagación transductiva, es decir controlándola y alimentándola en puesto fijo para hacer producir y trabajar en condiciones regulares" (2016, p. 149); y una organizadora, que establece "un régimen común de transducción y de modulación" en el que "la serie transductiva de decisiones es modulada por una información tomada sobre el conjunto del campo, el cual interviene así como una totalidad en el recorrido que lo recubre y lo transforma" (2016, p. 155). Transducción, modulación y organización son términos que Simondon extrae de diversas teorías y tecnologías, a fin de convertirlos en claves a la vez ontológicas y epistemológicas para comprender los procesos de individuación y, dentro de ellos, los procesos de información.

Se puede ver que la teoría filosófica de la información de Simondon, por la cual la información es concebida como procesos de amplificación y de individuación, toma distancia crítica respecto a la teoría tecnológica, aunque utilice algunos de sus términos. El filósofo francés emplea todo tipo de ejemplos (físicos, psicológicos, sociales, técnicos, biológicos) para dar cuenta de cada una de las amplificaciones, pues su objetivo es invertir la tendencia que se

19 Según Guchet (2010), en la conferencia Simondon acusa a los cibernéticos de "teorizar la operación que transforma una estructura en otra estructura (y ese es en efecto el objeto de una ciencia de las operaciones) a partir de una hipótesis que sigue siendo estructural: la transformación de una estructura en otra se haría necesariamente por intermedio de una tercera estructura" (p. 74; traducción nuestra). 
verifica en la cibernética. "Si el programa de la cibernética consiste en expandir el paradigma tecnológico a los sistemas biológicos y sociales, la intención de Simondon es la contraria. Apunta a expandir el paradigma psicosocial y/o biológico de la comunicación a los campos físicos y tecnológicos" (Bardin, 2015, p. 31; traducción nuestra).

A la luz de esa observación, y sobre la base de lo ya expuesto, podemos aclarar la segunda cuestión anteriormente planteada. Efectivamente, Simondon critica la teoría tecnológica de la información correspondiente a la primera cibernética y propone otras posibilidades para la teoría de la información y su aplicación al campo de las ciencias humanas. Para Simondon, la cibernética -lo que hoy llamaríamos "la primera cibernética"-, tuvo la intención de constituirse en paradigma para las ciencias humanas bajo la "excusa" de realizar un programa interdisciplinario de investigación. Sin embargo, ella solo tradujo las disposiciones epistémicas que constituyeron la información a términos propios de una ontología: la emergencia de la autorregulación termodinámica derivó en las propiedades "organizacionales" de la información, mientras la emergencia de la transmisión telecomunicacional derivó en su distinción respecto de la forma y de la materia.

Simondon plantea una concepción de la información diferente a la de la teoría tecnológica. Se trata de un planteamiento que, según Hui (2015), está en consonancia con lo que luego será conocida como "segunda cibernética" o cibernética de la cibernética, que se entreteje con las teorías de la complejidad y la autoorganización surgidas en la década de 1960, y con la consideración de la información como propiedad emergente de los sistemas.

La segunda cibernética o "cibernética de segundo orden" es un término introducido por Heinz Von Foerster, uno de los secretarios de las conferencias Macy, a principios de los años setenta. Alude en principio a una cuestión epistemológica relacionada con la inclusión del observador dentro del sistema observado, en la estela de los hallazgos de la física cuántica y su derivación en el principio de incertidumbre. Von Foerster (2006) plantea que si la cibernética "de primer orden", a través de la información, observaba sistemas con un propósito, en la cibernética de segundo orden "el observador entra en el sistema estipulando su propio propósito (2006, p. 92, 
énfasis en el original). De este modo, no hay sistemas objetivos, sino sistemas que se complejizan a partir de su propio funcionamiento y se autoorganizan estableciendo sus propios parámetros, de manera que la información no es una entidad definible fuera del sistema sino un producto de la interacción de las partes de ese sistema.

Las teorías de la complejidad y de la autoorganización están en la base de la identificación reconocida de la segunda cibernética con la llamada Teoría General de los Sistemas, para la cual los sistemas cibernéticos "primeros", esto es, los que aluden a la mera transmisión de información como entidad cerrada, son apenas un caso dentro de varios sistemas posibles (Von Bertalanffy, 1993). Esto permite precisar el lugar de la apuesta simondoniana dentro de las teorías de la información. Por un lado, cabe señalar lo siguiente: que la información no tenga una ontología propia, sino que sea una propiedad emergente de los sistemas autoorganizados, es congruente con la noción de campo, donde no existe distinción ni jerarquía, sino más bien interacción permanente entre los elementos y la totalidad; eso ahora se llamaría "sistema". Por otro lado, esta teoría no-tecnicista de la información hace posible distinguir a los objetos técnicos de los objetos informacionales, dado que estos últimos se refieren a cualquier entidad, sea artificial, natural o humana, cuyo funcionamiento en un contexto determinado hace "surgir" un tipo de información no subsumible a los procedimientos técnicos de transmisión. Con ello se confirma la importancia que tiene para Simondon la información a la hora de proveer un nuevo modo de comprender las ciencias humanas.

\section{La información en el marco de una transformación epistémica: Kittler y Simondon}

Hasta aquí hemos reconstruido, a partir de Kittler y Simondon, dos propuestas de renovación de las Humanidades que toman como eje la noción de información. En ambos casos, la información es considerada como una condición central de nuestras prácticas y saberes, es decir, como el a priori histórico de nuestro tiempo. A continuación, pondremos en relación ambas propuestas, 
considerando convergencias y divergencias, a fin de clarificar desafíos y posibilidades fundamentales de la tendencia general de renovación de las Humanidades que ambas representan.

En primer lugar, profundizaremos en la estrategia eliminacionista de Kittler y analizaremos las dificultades y desafíos que trae consigo. Posteriormente, recurriremos a Simondon como un correctivo que permitiría iluminar otras posibilidades para la renovación de las Humanidades, y finalmente tomaremos en consideración posibles aportes del planteamiento de Kittler para esclarecer el escenario actual.

El proyecto de Kittler acerca de un a priori técnico-medial, en su versión radicalizada, intenta excluir completamente el orden del sentido, esto es, "avanzar hacia un espacio libre de semántica" (Kittler, 1992, p. 67). Por "sentido" entiende Kittler no solamente la significación de los mensajes que circulan en un sistema de comunicación. También utiliza la expresión para indicar los contenidos que, según teorías aun dominantes, estarían producidos por instancias agenciales subjetivas o intersubjetivas. En conexión con ello, el autor recurre a la noción de sentido para señalar un conjunto de enfoques en ciencias sociales, filosofía y Humanidades, entre los que se cuentan la semiótica, la hermenéutica, las filosofías del sujeto, la filosofía del espíritu y en general la orientación hacia el "así llamado ser humano" (cfr. Kittler, 1999, pp. 22, 160, 229). En virtud de lo anterior, la "expulsión del Espíritu" y la concomitante orientación hacia la información pueden describirse como una operación de oposición y exclusión: información frente a sentido (cfr. Rubio, 2019). ${ }^{20}$

Uno de los principales argumentos de Kittler para apoyar tal exclusión sostiene que el código binario con el que opera la tecnología digital es un alfabeto universal que permite simular cualquier sistema de señales (visuales, acústicas, escriturales, etcétera) (cfr. Kittler, 2004, p. 249; 2009, p. 24; 2017, p. 65). En conexión con ello, Kittler

20 Kittler utiliza la noción de sentido programáticamente con el mismo alcance que la noción de "Espíritu" (cfr. Kittler, 1993b, p. 169; 2010, p. 44). Cabe distinguirla de las nociones de "símbolo" y "lo simbólico" que Kittler utiliza sobre todo a partir de su recepción de Lacan (cfr. Kittler, 1999, pp. 14-17; 2017, pp. 61 ss., 64 ss.; 2017c). El ámbito de lo simbólico es, conforme a dicha recepción, el dominio de la máquina, y en nuestro tiempo, el dominio del ordenador en cuanto máquina de información (cfr. Kittler, 2017c, pp. 138, 145). 
(1999) describe un escenario posthumanista en el que el "así llamado ser humano" cede su lugar a otras máquinas de información más eficaces (p. XXXIX).

Las visiones posthumanas de Kittler han despertado reacciones críticas no solamente en enfoques próximos a la filosofía del sentido (cfr. Mersch, 2006, pp. 27, 202-207), sino también en posiciones de orientación antihumanista sensibles a la tarea crítica de las Humanidades (cfr. Gane 2005; Winthrop-Young 2006, pp. 13-14). Un punto central del debate radica precisamente en la radicalidad de la propuesta eliminacionista. ¿Qué lugar le correspondería en el nuevo escenario a las cuestiones relativas a la afectividad, el poder, el género y otros tantos tópicos de la agenda de las Humanidades críticas? ¿Al excluir la dimensión del sentido, no se eliminaría también la potencia autocrítica de las Humanidades?

Este cuestionamiento se conecta también con un problema metodológico: la expulsión de toda dimensión semántica y la consagración del orden informacional como el único nivel de análisis volverían insostenible la distinción de órdenes (condicionante y condicionado) en la que se basa la orientación hacia un "a priori". La metáfora misma de la excavación arqueológica, según la cual se saca a la luz, en una operación crítica, un orden oculto que funciona como base del orden visible, comienza a diluirse ante la propuesta de un orden único de análisis.

A fin de considerar otras posibilidades del proyecto de renovación de las Humanidades a partir de la noción de información, que no estén expuestas a las dificultades mencionadas, conviene volver sobre los planteamientos de Simondon.

Para hacer lugar a la teoría de la información dentro de las ciencias humanas, Simondon -al igual que Kittler- excluye de su propuesta los enfoques semióticos, lingüísticos y hermenéuticos, los cuales se centran en el problema del "sentido". Y para ello, como el pensador alemán, reivindica el papel de la técnica y su integración dentro del campo de las investigaciones acerca de la cultura.

Por otra parte, sin embargo, el análisis de Simondon se separa del de Kittler en dos áreas centrales. En primer término, Simondon estima que la teoría matemática de la información no puede 
ser aislada del marco general de comprensión que le provee la cibernética, incluso para comprender de qué manera la aplicación de la noción de información a los más variados campos tecnocientíficos supera a su mera realización en tecnologías digitales, mediales y computacionales. En este sentido, la cibernética es para Simondon un intento de reorganizar el campo de las ciencias humanas alrededor de la teoría de la información; algo que en principio podría ser coincidente con su propio planteamiento y con el de Kittler.

En segundo término, hay que decir que la razón por la cual esta posible coincidencia no ha tenido lugar, es que, según Simondon, las posiciones mayoritarias de la primera cibernética se dirigen a exportar la teoría matemática de la información, sin grandes cambios, al resto de las ciencias humanas, sin discutir la definición misma de información. Y esto, que aproximaría a Kittler con la primera cibernética, distancia a ambos del propio Simondon, pues allí donde el alemán, en línea directa con el análisis del propio Shannon, distingue información de sentido, el francés señalará tres términos: señal, información y significación, sin que esta última esté restringida a los seres humanos; de allí que "significación" para Simondon no equivalga a lo que sostienen la lingüística o la semiología, pero tampoco al "sentido", según la fenomenología o la hermenéutica. ${ }^{21}$

En el proyecto filosófico de Simondon, la información tiene un volumen conceptual propio pues "produce nuevos niveles de realidad", y en este sentido la referencia tecnológica y medial, e incluso el hecho de "subsumir todos los medios a los datos digitales", como hace Kittler, sería insuficiente (Mills, 2016, p. 184).

Ahora bien, si hasta aquí hemos recurrido a Simondon como un posible correctivo frente a los excesos de la posición radicalizada de Kittler, ${ }^{22}$ corresponde ahora volver a Kittler para repensar el escenario actual. En otras palabras, cabe advertir que Simondon reivindica

21 La teoría de la individuación de Simondon apunta precisamente a escapar de la dicotomía de su época entre estructuralismo y fenomenología. Para un análisis de las condiciones epistémicas de la postura simondoniana, véase Heredia (2016).

22 En el presente trabajo nos hemos concentrado en la estrategia eliminacionista del Espíritu y del sentido que caracteriza al materialismo teórico-informacional de Kittler. Esto no excluye, por cierto, la posibilidad de elaborar líneas de desarrollo menos radicalizadas a partir de Kittler como, por ejemplo, una interpretación que privilegie la versión débil del a priori medial. 
una distancia entre ser humano y máquina que el desarrollo de las tecnologías de información, posterior a 1958 (año de la escritura de sus libros), se encargó de desmentir, o al menos relativizar. De este modo, es Kittler quien, con ese desarrollo ya conocido, nos permite "entender las implicaciones epistémicas del cambio tecnológico" (Mills, 2016, p. 184) que no necesitan pasar forzosamente por la filosofía simondoniana. Kittler muestra que "la tecnología puede operar debajo del umbral de lo sensible y lo cognitivo" y, así, que "los medios desbordan la capacidad de la conciencia humana" (Mills, 2016, p. 185; traducción nuestra), como se puede observar actualmente respecto del Big Data, los algoritmos que "evolucionan" y las plataformas digitales que realizan actividades desconocidas para sus usuarios.

\section{Palabras finales}

Kittler y Simondon nos invitan a pensar la información como el nuevo a priori histórico, en un gesto que, con características propias en cada caso, retoma y a la vez transforma la formulación clásica de Foucault sobre las ciencias humanas.

En el caso de Kittler, se trata de una asunción explícita: la noción de a priori técnico de los medios es una reelaboración del a priori histórico de las ciencias humanas que señala un camino diferente al que pensó Foucault (cfr. Rodríguez, 2019). En el caso de Simondon, la incorporación de la información en la reflexión se produce a través del marco más amplio de la episteme moderna, que para Foucault era la realización de aquel a priori histórico en el campo de las ciencias y de las formaciones discursivas que tematizan "lo humano". Al identificar ese marco, Simondon encuentra un discurso y una práctica que aspira precisamente a plantear otro tipo de Humanidades, entrelazado íntimamente con la técnica y la información: la cibernética. La crítica simondoniana a la cibernética señala los límites de la aplicación de la teoría matemática de la información a las Humanidades y denuncia, como consecuencia de la exportación acrítica de sus supuestos, un reduccionismo tecnológico en el cual se podría incluir a Kittler.

No es propósito de este trabajo resolver ni disolver las tensiones 
entre Kittler y Simondon, sino más bien ponerlas de relieve sobre el trasfondo de un énfasis común en la información en cuanto condicionante de nuestro tiempo. En el contexto actual de las teorías sobre posthumanidades, transhumanismo, antihumanismo, etcétera, el estudio de las divergencias y convergencias de los dos planteamientos considerados aporta elementos de discusión específicos para enriquecer el debate, como, por ejemplo, la discusión respecto a la relevancia (o no) de la dimensión semántica en los procesos informacionales, o la discusión sobre el estatuto trascendental de la instrumentalidad técnica $\mathbf{I}$

\section{Referencias}

Bardin, A. (2015). Epistemology and political philosophy in Gilbert Simondon. Springer.

Clarke, B. (2010). Information. En M. Hansen y W. J. T. Mitchell (Eds.), Critical Terms for Media Studies (pp. 157-171). University of Chicago Press.

Deleuze, G. (2005). Anexo: Sobre la muerte del hombre y el superhombre. En Foucault (pp. 159-170). Paidós.

Dupuy, J-P. (1999). Aux origines des sciences cognitives. La Découverte.

Ebeling, K. (2006). Das technische Apriori. En L. Engell et al. (Eds.), Kulturgeshichte als Mediengeschichte (oder vice versa?) (pp. 11-21). Fink.

Ebeling, K. (2017). Archéologies sauvages: Freud et Foucault au péril de Kittler. Appareil, (19), 1-21. 2017. https://doi.org/10.4000/appareil.2537

Ernst, W. (2013). From Media History to Zeitkritik. Theory, Culture $\mathcal{E}$ Society, 30(6), 132-146. https://doi.org/10.1177/0263276413496286

Foucault, M. (1997). Las palabras y las cosas. Siglo XXI.

Foucault, M. (2002). La arqueología del saber. Siglo XXI.

Gane, N. (2005). Radical Post-Humanism. Friedrich Kittler and the Primacy of Technology. Theory, Culture Eु Society, 22(3), 25-41. https://doi.org/10.1177/0263276405053718

Geoghegan, B. (2013). After Kittler: On the Cultural Techniques of recent 
German Media Theory. Theory, Culture EF Society, 30(6), 66-82. https://doi.org/10.1177/0263276413488962

Guchet, X. (2010). Pour un humanisme technologique. Culture, technique et société dans la philosophie de Gilbert Simondon. Presses Universitaires de France.

Hartmann, F. (2008). Friedrich Kittler. En U. Sander et al. (Eds.), Handbuch Medienpädagogik (pp. 251-256). Springer.

Heims, S. (1991). The Cybernetics Group. Constructing a Social Science for Post-war America. MIT Press.

Heredia, J.M. (2016). La invención de la individuación a la luz de una problemática histórico-epistemológica. Páginas de Filosofía, (20), 59. 82. https://bit.ly/2ZXjonI

Hoel, A. S. y Van der Tuin, I. (2013). The Ontological Force of Technicity: Reading Cassirer and Simondon Diffractively. Philosophy $\mathcal{E}$ Technology, 26(1), 187-202. https://link.springer.com/article/10.1007/ s13347-012-0092-5

Hui, Y. (2015). Simondon et la question de l'information. Cahiers Simondon 6. L'Harmattan.

Kittler, F. (1985). Aufschreibesysteme 1800 / 1900. Fink.

Kittler, F. (1990). Discourse Networks 1800 / 1900. Stanford University Press.

Kittler, F. (1993a). Draculas Vermächtnis. Reclam.

Kittler, F. (1993b). Geschichte der Kommunikationsmedia. En J. Huber et al. (Eds.), Raum und Verfahren (pp. 169-188). Stroemfeld.

Kittler, F. (1999). Gramophone, Film, Typewriter. Stanford University Press.

Kittler, F. (2002). Short cuts. Zweitausendeins.

Kittler, F. (2004). Universities: Wet, Hard, Soft, and Harder. Critical Inquiry, 31(1), 244-255. https://doi.org/10.1086/427310

Kittler, F. (2009). Towards an Ontology of Media. Theory, Culture $\mathcal{E}$ Society, 26(2-3), 23-31. https://doi.org/10.1177/0263276409103106

Kittler, F. (2010). Optical media. Polity Press. 
Kittler, F. (2013). The Truth of the technological World. Stanford University Press.

Kittler, F. (2017a). No hay software y otros ensayos sobre tecnología. Editorial Universidad de Caldas.

Kittler, F. (2017b). Exorciser l'homme des sciences humaines: programmes du poststructuralisme. Appareil, (19), 1-8. https://doi.org/10.4000/ appareil.2522

Kittler, F. (2017c). El mundo de lo simbólico - Un mundo de las máquinas. Canal, (1), 121-158.

Kittler, F. (Ed.). (1980). Austreibung des Geistes aus den Geisteswissenschaften. Schöningh.

Krämer, S. (2006). The Cultural Techniques of Time Axis Manipulation. On Friedrich Kittler's Conception of Media. Theory, Culture $\mathbb{E}$ Society, 23(7-8), 93-109. https://doi.org/10.1177/0263276406069885

Mersch, D. (2006). Medientheorien zur Einführung. Junius.

Mills, S. (2016). Gilbert Simondon: Information, Technology and Media. Rowman \& Littlefield.

Parikka, J. (2012). Media Theory and New Materialism. En What is Media Archaeology? (pp. 63-70). Wiley.

Pias, C. (2016). What's German about German Media Theory? En N. Friesen (Ed.), Media Transatlantic (pp. 15-27). Springer.

Rodríguez, P. (2012). Historia de la información. Del nacimiento de la estadística y la matemática moderna a los medios masivos y las comunidades virtuales. Capital Intelectual.

Rodríguez, P. (2019). Del nuevo apriori histórico. En P. Rodríguez, Las palabras en las cosas. Saber, poder y subjetivación entre algoritmos y biomoléculas (pp. 59-82). Cactus.

Rubio, R. (2019). El legado materialista de Heidegger. Veritas, (44), 9-28. http://dx.doi.org/10.4067/S0718-92732019000300009

Shannon, C. y Weaver, W. (1949). The Mathematical Theory of Communication. The University of Chicago Press.

Simondon, G. (2008). El modo de existencia de los objetos técnicos. Prometeo. 
Simondon, G. (2015). La individuación a la luz de las nociones de forma y de información. Cactus.

Simondon, G. (2016). Comunicación e información: Cursos y conferencias. Cactus.

Triclot, M. (2008). Le moment cybernétique. La constitution de la notion d'information. Champ Vallon.

Von Bertalanffy, L. (1993). Teoría general de los sistemas: Fundamentos, desarrollo, aplicaciones. Fondo de Cultura Económica.

Von Foerster, H. (2006). Cibernética de la cibernética. En Las semillas de la cibernética. Obras escogidas (ed. Marcelo Pakman). Gedisa.

Wiener, N. (1971). Cibernética. Guadiana de Publicaciones.

Winthrop-Young, G. (2006). Cultural studies and German media theory. En G. Hall y C. Birchall (Eds.), New Cultural Studies: Adventures in Theory (pp. 88-104). Edinburgh University Press. 